\title{
Late-Holocene climate evolution at the WAIS Divide site, West Antarctica: bubble number-density estimates
}

\author{
J.M. FEGYVERESI, ${ }^{1}$ R.B. ALLEY, ${ }^{1}$ M.K. SPENCER, ${ }^{2}$ J.J. FITZPATRICK, ${ }^{3}$ E.J. STEIG, ${ }^{4}$ \\ J.W.C. WHITE, ${ }^{5}$ J.R. MCCONNELL, ${ }^{6}$ K.C. TAYLOR ${ }^{6}$ \\ ${ }^{1}$ Department of Geosciences, The Pennsylvania State University, and The Earth and Environmental Systems Institute, \\ University Park, Pennsylvania 16802, USA \\ E-mail: jmf439@psu.edu \\ ${ }^{2}$ Department of Geology and Physics, Lake Superior State University, Sault Ste. Marie, Michigan 49783, USA \\ ${ }^{3}$ US Geological Survey, Geology and Environmental Change Science Center, PO Box 25046, MS 980, \\ Denver, Colorado 80225, USA \\ ${ }^{4}$ Department of Earth and Space Sciences and Quaternary Research Center, University of Washington, \\ Seattle, Washington 98195, USA \\ ${ }^{5}$ Institute of Arctic and Alpine Research, UCB 450, University of Colorado at Boulder, Boulder, Colorado 80309-0450, USA \\ ${ }^{6}$ Desert Research Institute, 2215 Raggio Parkway, Reno, Nevada 89512-1095, USA
}

\begin{abstract}
A surface cooling of $\sim 1.7^{\circ} \mathrm{C}$ occurred over the $\sim$ two millennia prior to $\sim 1700 \mathrm{CE}$ at the West Antarctic ice sheet (WAIS) Divide site, based on trends in observed bubble number-density of samples from the WDC06A ice core, and on an independently constructed accumulation-rate history using annual-layer dating corrected for density variations and thinning from ice flow. Density increase and grain growth in polar firn are both controlled by temperature and accumulation rate, and the integrated effects are recorded in the number-density of bubbles as the firn changes to ice. Numberdensity is conserved in bubbly ice following pore close-off, allowing reconstruction of either paleotemperature or paleo-accumulation rate if the other is known. A quantitative late-Holocene paleoclimate reconstruction is presented for West Antarctica using data obtained from the WAIS Divide WDC06A ice core and a steady-state bubble number-density model. The resultant temperature history agrees closely with independent reconstructions based on stable-isotopic ratios of ice. The $\sim 1.7^{\circ} \mathrm{C}$ cooling trend observed is consistent with a decrease in Antarctic summer duration from changing orbital obliquity, although it remains possible that elevation change at the site contributed part of the signal. Accumulation rate and temperature dropped together, broadly consistent with control by saturation vapor pressure.
\end{abstract}

\section{INTRODUCTION}

Knowledge of climate history is of value in understanding and attributing climate change (e.g. Solomon and others, 2007). Ice cores contribute in important ways, supplementing and extending instrumental data (e.g. Schneider and Steig, 2008; Steig and others, 2009). Data from ice cores are especially valuable because they provide multiple, independent constraints on the history of key climatic variables such as temperature (e.g. Cuffey and Paterson, 2010).

Ice-core techniques for estimating past temperatures include the interpretation of stable-isotope ratios of ice $\left(\delta^{18} \mathrm{O}\right.$ or $\delta \mathrm{D} ;$ e.g. Epstein and others, 1970$)$, occurrence of melt layers (e.g. Das and Alley, 2008), thermal fractionation of gases under temperature gradients across firn, and depth or age of firn (e.g. Severinghaus and others, 1998), together with the inversion of temperatures measured in boreholes (e.g. Cuffey and others, 1994). All of these have a strong basis in physics but are influenced by processes other than simply temperature change.

Spencer and others (2006) showed that bubble numberdensity in polar ice can be quantitatively modeled as a function of temperature and accumulation rate. Here we apply their model to new bubble number-density data obtained from an ice core at the West Antarctic ice sheet (WAIS) Divide site to produce a new paleoclimate reconstruction for the $\sim$ two millennia prior to $\sim 1700 \mathrm{CE}$.
The WAIS Divide drilling site (Fig. 1) is located at $79^{\circ} 28.058^{\prime} \mathrm{S}, 112^{\circ} 05.189^{\prime} \mathrm{W}, \sim 160 \mathrm{~km}$ from the previous Byrd ice-core drilling site and $\sim 24 \mathrm{~km}$ from the current West Antarctic ice-flow divide (on the Ross Sea side). This drilling location was chosen because it provides an excellent hightime-resolution analogue to the central Greenland ice cores, in terms of ice accumulation rate $\left(\sim 22 \mathrm{~cm} \mathrm{a}^{-1}\right)$, thickness $(\sim 3465 \mathrm{~m})$, average annual surface temperature $\left(-31.1^{\circ} \mathrm{C}\right)$, and gas-age-ice-age difference ( $\sim 225$ years) (Conway and others, unpublished).

\section{BUBBLE NUMBER-DENSITY PALEOCLIMATOLOGY}

The technique of Spencer and others (2006) allows reconstruction of either paleotemperatures or paleo-accumulation rates by fitting a semi-empirical steady-state model to measured number-densities of bubbles in (ice-core) glacier ice (see also Lipenkov and others, 1998; Alley and Fitzpatrick, 1999). Temperature and accumulation rate are the primary drivers of polar firn densification, and the integrated effects of these two drivers on density and grain growth are recorded in the number-density of bubbles formed during the sintering process as the firn is transformed into ice at the pore close-off depth (Spencer, 1999; Spencer and others, 2006). That number-density is then conserved in the bubbly ice following pore close-off. This allows use of a 


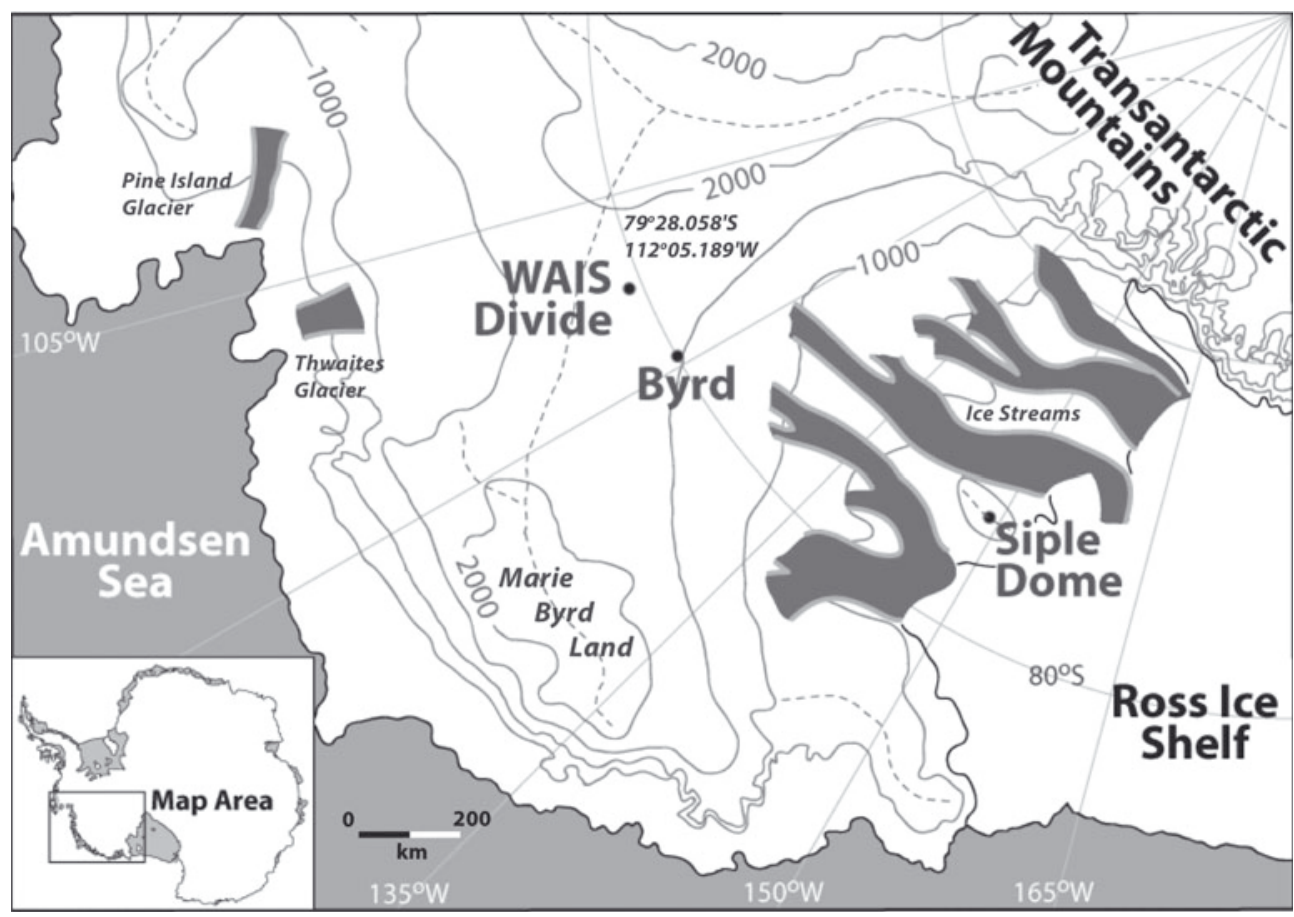

Fig. 1. Map of West Antarctica showing the WAIS Divide, Byrd and Siple Dome ice-core drilling locations. The WAIS Divide WDC06A icecore site is located at $79^{\circ} 28.058^{\prime} \mathrm{S}, 112^{\circ} 05.189^{\prime} \mathrm{W}, \sim 160 \mathrm{~km}$ from the Byrd ice-core drilling site, $\sim 24 \mathrm{~km}$ from the current West Antarctic ice-flow divide and $\sim 1640 \mathrm{~km}$ from McMurdo station. The ice at the WAIS Divide site is $\sim 3465 \mathrm{~m}$ thick, with a bed elevation of $\sim 1700 \mathrm{~m}$ below sea level. Contours represent surface elevation $(\mathrm{m})$. Figure modified from Conway and others (unpublished).

combined firn-densification/grain-growth model to invert for either the firnification paleotemperature or paleo-accumulation rate, provided the other parameter is known, as described by Spencer and others (2006). Here we define pore close-off depth as the depth at which firn has reached a total density of $\sim 90 \%$ that of the average ice density (Herron and Langway, 1980).

Accumulation rate can be determined independently for the WAIS Divide site, as described below, so we use bubble data to solve for temperature history here. The transformation of snow to firn, and ultimately to ice, is principally governed by the temperature and by the weight of overlying accumulated snow (Gow, 1968b). In higher-accumulation environments, this process is achieved more rapidly due to greater overburden pressures. The crystal size at the depth of bubble trapping is controlled by the time to transformation, and by the crystal growth rate, which is primarily controlled by temperature. For these reasons, faster transformation is favored by higher temperature and/or higher accumulation rate. Faster transformation in turn gives a smaller gas-ageice-age difference, and climate records from bubble number-density with higher time resolution.

Because of this dependence on accumulation rate and temperature, there are large geographic variations in pore close-off depths and firnification times. At higher-accumulation sites such as WAIS Divide, Antarctica, or Summit, Greenland, pore close-off takes only a few hundred years, and may even be achieved in decades at sites of exceptionally high accumulation such as parts of Law Dome, Antarctica. In contrast, at a low-accumulation site such as Vostok, Antarctica, the process can take a few thousand years and is significantly more sensitive to slow temporal accumulation-rate changes (i.e. rate changes through interglacial/glacial transitions) (Sowers and others,
1992). The captured bubbles in glacier ice thus preserve a record of environmental conditions during the time that the enclosing ice was still firn, with time resolution that depends on accumulation rate and temperature. Note, however, that the pore close-off process is not instantaneous, introducing slight additional smoothing. For WAIS Divide, pore close-off depth is identified at $\sim 823 \mathrm{~kg} \mathrm{~m}^{-3}$ ice density $(90 \%$ of average ice density for the study sample set).

Gow (1968a) argued that the geometry of firn at pore close-off is essentially self-similar, meaning that larger grains at pore close-off produce fewer but larger bubbles. During burial following pore close-off, the ice grain size itself quickly becomes an unreliable indicator of firnification conditions due to various processes (growth, nucleation and splitting of grains) that depend on the ice deformation rate and not just on temperature and accumulation rate (Alley and others, 1995; Spencer and others, 2006). However, bubble number-densities in ice reliably preserve information about firnification conditions for a longer time, due to the slow diffusion between bubbles (Ikeda-Fukazawa and others, 2001, 2005) and the near absence of bubble coalescence or splitting in most ice-sheet situations (Alley and Fitzpatrick, 1999). It is important to note, however, that bubbles are known to preserve this information only until they collapse into clathrate-hydrate crystals under sufficiently high burial pressures (e.g. Shoji and Langway, 1982; Salamatin and others, 1998; Pauer and others, 1999); it remains unclear whether original bubble number-density can be estimated quantitatively from clathrate number-density or from bubbles formed by relaxation of clathrate-containing ice.

For the WAIS Divide site, the bubble-clathrate zone was observed to begin at $\sim 1100-1200 \mathrm{~m}$ depth, which equates to an age of only $\sim 5 \mathrm{ka}$ because of the high accumulation rate. However, this high accumulation rate allows the 
technique to give relatively high time resolution, averaging over the $\sim 225$ years to reach the close-off depth at the modern accumulation rate. Here we concentrate on the more recent part of the bubble record, because the older section is in 'brittle ice', with air pressures in bubbles sufficiently high to cause fracturing during sample preparation; we plan to extend measurements after the brittle ice has relaxed enough to be analyzed properly.

\section{METHODS AND DATA}

In order to employ the bubble number-density model and create the temperature reconstructions in this study, both bubble number-density data and accumulation rates were necessary. Bubble number-density data were acquired by preparing, digitally imaging and analyzing bubble thin sections obtained from ice at 23 depths from the WDC06A WAIS Divide ice core. Accumulation rates necessary for the model were estimated from ice-layer thickness after correcting for ice-flow strain and densification. For dating purposes, a depth-age scale for the WDC06A based on annual layers resolved in chemistry data was used.

Ice-core bubble thin sections for measurement of bubble number-densities were prepared either in the field or at the US National Ice Core Laboratory (NICL)'s $-26^{\circ} \mathrm{C}$ sample-preparation room. First, single-piece $10 \mathrm{~cm}$ long samples were cut from the appropriate WDC06A ice-core sections; typically, both vertical and horizontal sections were prepared. The vertical sections cannot be oriented unambiguously relative to the ice-flow direction, but the near isotropy of bubbles observed in horizontal sections means that no bias is introduced by this difficulty when we use a typical bubble size to correct for cut-bubble effects in section analysis, as described below. Samples were collected at $\sim 20 \mathrm{~m}$ depth intervals. In total, the 23 samples from the WDC06A ice core (cut on-site during the 2007/08 WAIS Divide field season) were taken at depths ranging from 120 to $562 \mathrm{~m}$. Before cutting and preparing the bubble thin sections, these $10 \mathrm{~cm}$ samples were first used for total icedensity measurements.

Densities were measured by submerging the $10 \mathrm{~cm}$ ice samples on a metal 'basket' into a small reservoir of isooctane, measuring the volumetric displacement and making the necessary buoyancy corrections to allow for the effect of the basket (Gow and others, 1997). Measured densities increased smoothly to $915 \mathrm{~kg} \mathrm{~m}^{-3}$ at $\sim 260 \mathrm{~m}$. The technique is potentially accurate to $\pm 0.3 \mathrm{~kg} \mathrm{~m}^{-3}$, but variability between successive deeper samples was $\sim \pm 1 \mathrm{~kg} \mathrm{~m}^{-3}$, perhaps owing to microcracking marking the very earliest influence of brittle-ice behavior. Changes in porosity from bubble compression are estimated to be sufficiently small below $260 \mathrm{~m}$ (Gow, 1968a) that we adopted $915 \mathrm{~kg} \mathrm{~m}^{-3}$ for deeper samples, together with a spline fit for samples between 120 and $260 \mathrm{~m}$. For samples from 0 to $120 \mathrm{~m}$ $\left(400-900 \mathrm{~kg} \mathrm{~m}^{-3}\right)$, densities were determined on-site by the volume-mass technique (personal communication from T. Sowers, 2008).

Following density measurement, a vertically oriented slab of ice $\sim 1.5 \mathrm{~cm}$ thick was cut from the side of the sample using a bandsaw, followed by a $\sim 1.5 \mathrm{~cm}$ thick horizontally oriented piece from the top of the sample. Each of these smaller samples was then cleaned using a microtome, sandwiched between glass plates, and bonded using a bead of water on the perimeter of the sample (use of glue on potential bubble sections was avoided because of the possibility of introducing bubbles in the glue).

After setting, each sample was cut in half using a bandsaw to create two separate thin $(\sim 5 \mathrm{~mm})$ samples bound on one side by glass, with one sample destined for thin-section analysis and the other for bubble analysis. The bubble sections were microtomed to a thickness of $\sim 1.25 \mathrm{~mm}$ to ensure that they were thin enough that interpretation would not be complicated by numerous bubbles overlapping one another. Samples thinner than $\sim 1.25 \mathrm{~mm}$ are prone to breakage during microtoming. Finally, sample ice thicknesses were determined by taking measurements of overall sample thickness (including glass plates) and glass-plate thickness alone using a precision digital vernier caliper. Each sample was photographed, with scale, using a Nikon D80 camera (and 18-135 mm ZoomNikkor lens) at the NICL on a side-lit stage in a dark room.

Raw images were processed to obtain bubble numberdensity data (Fig. 2). An area of $\sim 150 \mathrm{~mm}^{2}$ was selected on each sample that was most free of smudges, cracks or other marks and thus provided the cleanest and most consistent area of the bubble section. This size was chosen in order to provide enough bubbles to prevent statistical fluctuations in the results, but without generating too much work for the analysts. Assisted by an edge-detection algorithm, rare remaining non-bubbles (i.e. smudges, glass marks, cracks, etc.) were shaded out and removed, while partial bubbles (those for which the illumination had not produced a completely closed convex figure in the image) were manually edited to elucidate more clearly ambiguous edges, or removed if located on one of the image edges (see Equation (1) below). Next, each edited image was converted into an eight-bit binary image, using the same threshold in all cases, in order to highlight the bubbles and improve identification of bad pixels and overlooked spots. Finally, colored versions of the binary images were overlain on their originally edited counterparts to check for any outstanding errors. Extensive checking shows that our thresholds are set such that we do not introduce spurious 'bubbles', so that there is no need to conduct a second check by overlaying the original image on the binary image.

This complete process was applied to two non-overlapping areas of each raw bubble-section image, and the average was used in our calculations. In addition, the entire image-processing procedure was repeated independently by a different analyst for each of these areas on each image to establish reproducibility. After all final image reads and edits were completed, software scripts were used to automatically measure all of the bubble features and pertinent data. In addition to bubble number-density, various other bubble statistics were measured for potential future use (e.g. average inscribed bubble radius, bubble elongation, bubble perimeter, etc.).

The bubble number-density is the count of bubbles with centers that fall within a specified volume. However, because bubbles are not geometrical points, some bubbles with centers outside a sample volume will be cut by the sides or the upper or lower faces of the sample, and thus will appear within the sample. Corrections must thus be made (e.g. Underwood, 1970). The corrections are simplified by the fairly narrow size distribution exhibited by the bubbles, allowing us to use the mean bubble size, taken as the average inscribed radius, $R$, returned by the software. (This introduces a very minor error because the bubbles centered 

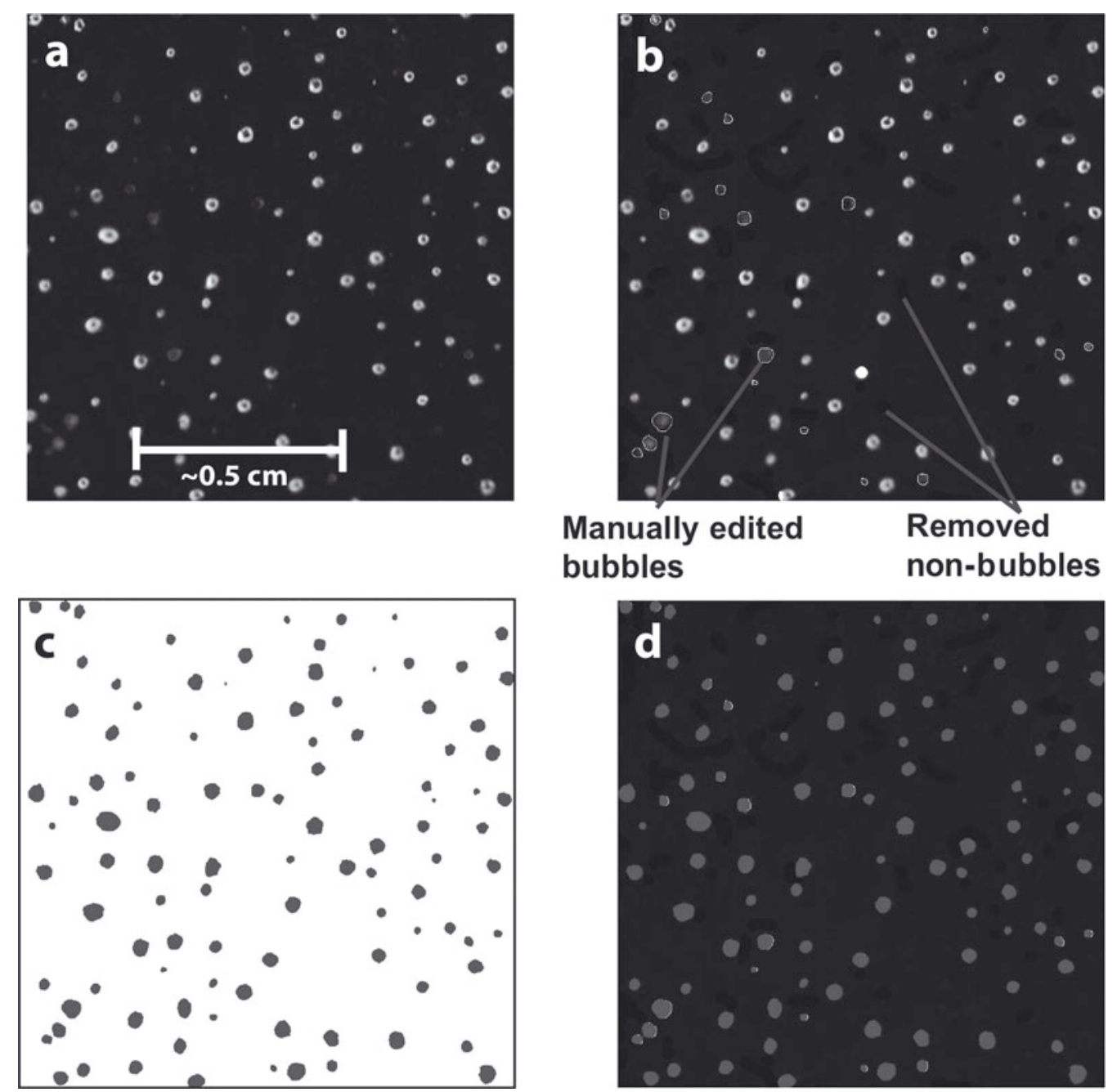

Fig. 2. Four-step 'clean-up' process used on $\sim 150 \mathrm{~mm}^{2}$ bubble sections: (a) raw data; (b) non-, partial and edge bubbles blacked out, with ambiguous bubble edges drawn in for clarity (examples noted); (c) after binary conversion, with bubbles highlighted for clarity and bad pixels edited out; and (d) the final step of overlaying the binary on (b) to check for errors.

outside the sample influence the average value, but, based on our experience, use of a full Saltykov-type correction would introduce much greater error (Underwood, 1970; Alley, 1987).) We eliminated all bubbles touching the sides of our $L \times L$ square sampling regions (where $L$ is the edge length), which is equivalent to counting only those bubbles with centers at least a distance $R$ inside the squares. We cannot similarly tell which bubbles have centers above the upper face or below the lower face of a sample, so we count all bubbles with centers in a volume extending a distance $R$ above the upper face and $R$ below the lower face. Using measured ice thicknesses and including these corrections, the final calculated bubble number-density can be represented by

Bubble number-density $=\frac{\text { Number of bubbles }}{\left[(\text { Thickness }+2 R)(\text { Length }-2 R)^{2}\right]}$

One additional minor correction was needed. Bubbles form at approximately atmospheric pressure, and are then compressed fairly rapidly until the internal bubble pressure nearly equals the ice overburden pressure. Further compression is then very slow to maintain the internal pressure at the ice overburden pressure, until clathrate formation removes the bubbles (Gow, 1968a). The finite thickness of a sample, together with the progressive vertical compaction of the ice column from this bubble compression, causes the number of bubbles with centers within a given thickness to increase slightly with depth. This is not a climatic effect and must be corrected for. Here a correction is made to the ice density of $915 \mathrm{~kg} \mathrm{~m}^{-3}$ using

$$
B_{\mathrm{C}}=\frac{B_{\mathrm{O}} \rho_{\mathrm{A}}}{\rho_{\mathrm{M}}}
$$

where $B_{\mathrm{O}}$ is the observed bubble number-density (bubbles $\mathrm{cm}^{-3}$ ), $\rho_{\mathrm{M}}$ is the measured ice density for the given sample $\left(\mathrm{kg} \mathrm{m}^{-3}\right), \rho_{\mathrm{A}}$ is the calculated average ice density $\left(\mathrm{kg} \mathrm{m}^{-3}\right)$ and $B_{C}$ is the corrected bubble number-density (bubbles $\mathrm{cm}^{-3}$ ). (In all cases, this correction is quite small. Note also that the incompressible strain of ice from ice-sheet flow increases the horizontal distance between bubble centers while decreasing the vertical distance. Thus the net effect on bubble number-density is zero, so no correction is needed.)

For each horizontal and vertical sample, four separate readings (two readings each for two independent analysts) were averaged together to arrive at a single corrected bubble number-density value; the mean and standard deviation are 


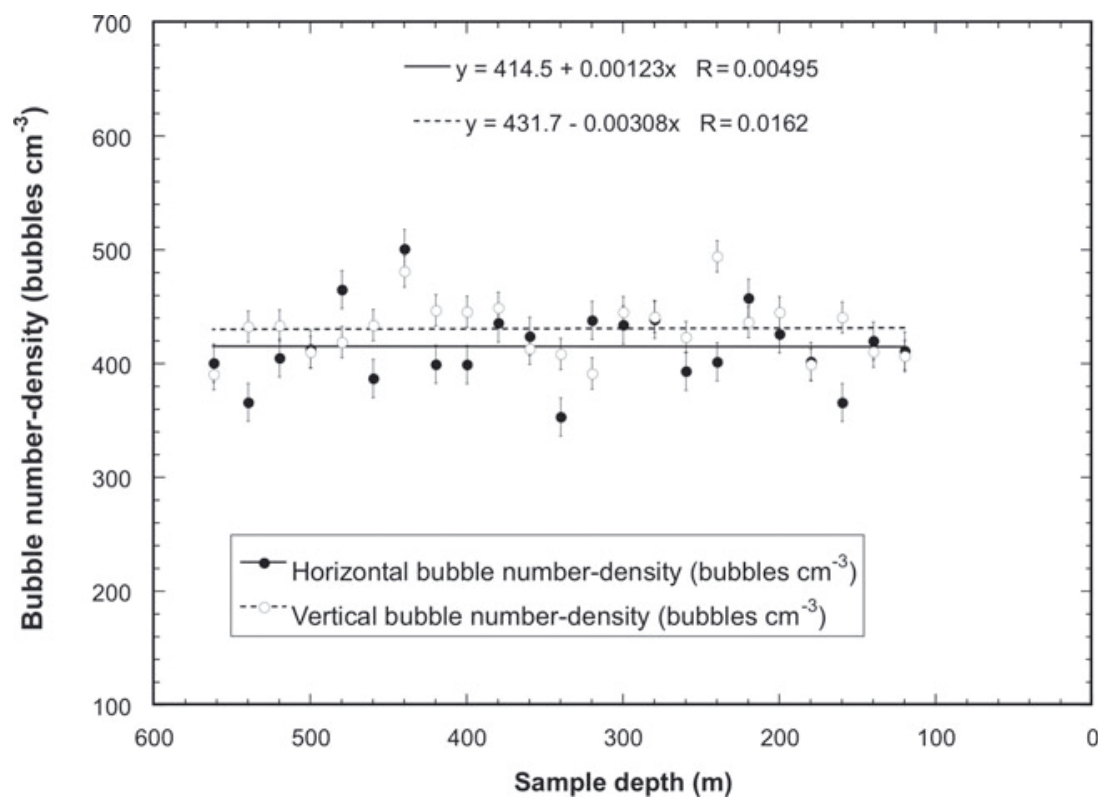

Fig. 3. Final horizontal and vertical bubble number-densities plotted against depth. Error bars are $1 \sigma$ uncertainty of reproducibility across samples.

plotted against depth in Figure 3. The $1 \sigma$ error in bubble number-density (bubbles $\mathrm{cm}^{-3}$ ) is \pm 16.78 horizontally and \pm 13.74 vertically.

\section{COMPUTATIONS AND RESULTS}

As discussed by Spencer and others (2006), the bubble number-density depends on the integrated effect of the accumulation rate and temperature on firn densification and grain growth over the time interval between snow deposition and bubble close-off. An ultimate goal is to develop fully time-dependent inverse techniques for paleoclimatic reconstructions. However, when climate changes are relatively small and slow (as indicated post facto for the WAIS Divide site, and as expected for most sites during the Holocene), a useful short cut is to apply forward modeling to map the dependence of bubble number-density on constant accumulation rate and temperature spanning all possible combinations with degree and millimeter precision. Then an average accumulation rate over a specific interval can be used in conjunction with this map to estimate the average temperature over the time from deposition to bubble formation. Pending development of a time-dependent inverse technique, we follow the pseudo-steady-state approach here, using the accumulation-temperature-bubble mapping of Spencer and others (2006). We further estimate accumulation rates averaged over $57 \mathrm{~m}$ (ice) thickness, the approximate modern value for the depth to pore close-off, assumed constant over time, and corrected for thinning from ice flow. In times of strong accumulation-rate change, this assumption could cause use of a significantly erroneous average value, but post facto it introduces little error.

Accumulation rate can be estimated from ice-flow correction of an accurate depth-age scale; at the shallow depths considered here, the uncertainties in the flow correction are small (e.g. Cuffey and Paterson, 2010). Annual layers in the WAIS Divide ice core have been counted using various techniques including visible identification, dielectric properties analysis and chemical analysis (e.g. Taylor and others, 2004; Banta and others, 2008; McGwire and others, 2008). The techniques generally agree well. The chemistry-based depth-age scale is believed to provide the most accurate representation of annual-layer timing and thicknesses, and was therefore used in this study.

Raw annual-layer thicknesses from the chemistry-based depth-age scale were corrected first for density, and second for plastic deformation by way of an ice-flow model with constant strain rate with depth (Nye, 1963):

$$
T_{\mathrm{O}}=\frac{T_{\rho} H}{Z},
$$

where $T_{\rho}$ is the density-adjusted layer thickness $(\mathrm{cm}), H$ is the total ice-sheet thickness at WAIS Divide (3465 m), $Z$ is the height of the given layer from the bed of the ice sheet $(\mathrm{m})$ and $T_{O}$ is the final ice-flow and density-corrected layer thickness $(\mathrm{cm})$, or ice equivalent accumulation rate. Layer thicknesses (and thus ice accumulation rates) are plotted against their age over the last $\sim 2400$ years (Fig. 4). At greater depths, a more accurate flow model will be required, but little error is introduced here. The general trend toward lower accumulation rate with time agrees with the results of Neumann and others (2008). The greatest potential source of error is in the dating, but we believe that errors are $<1 \%$. Uncertainties in accumulation due to density, thickness and ice-flow correction were too small to appear clearly in figures or notably affect the calculations.

For each horizontal and vertical sample in this study, a paleotemperature was determined using the bubble numberdensity, average accumulation rate, and modeled steadystate values of Spencer and others (2006; see their fig. 4 for graphical representation of the full tabular output). Little change in bubble number-density occurs across the dataset (Fig. 3). The trend toward lower accumulation rate with time (Fig. 4) favors fewer, larger bubbles. The constant bubble number-density thus indicates a synchronous cooling, which favors more but smaller bubbles. This result is evident in the calculated temperatures as shown in Figure 5. The model error for determination of absolute temperature from Spencer and others (2006) is $\pm 0.9^{\circ} \mathrm{C}$. Our counting reproducibility, 


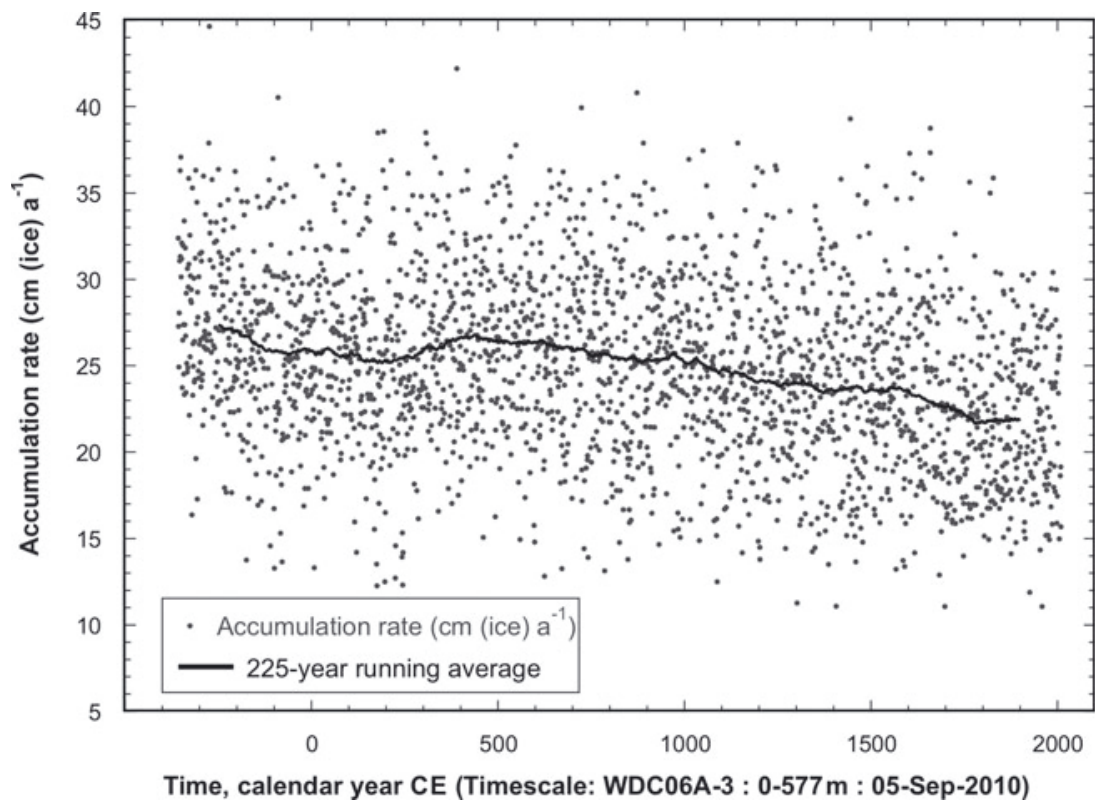

Fig. 4. WAIS Divide accumulation rates calculated after density and ice-flow strain correction. The black curve is a 225 year running average.

and thus our measurement error contributing to uncertainty in temperature changes, is $\pm 0.5^{\circ} \mathrm{C}$. Regression of the results shown in Figure 5 yields trends over the complete dataset of $\sim 1.65^{\circ} \mathrm{C}$ and $\sim 1.67^{\circ} \mathrm{C}$ for horizontal and vertical samples, respectively, with $95 \%$ uncertainty of $\sim 1^{\circ} \mathrm{C}$. There is no reason to believe the trend is linear, but inspection of the data, or comparison of points from early and late in the history, indicate a decrease of slightly less than $2^{\circ} \mathrm{C}$. For now, we take our regression result as our best estimate, indicating a decrease of $\sim 1.66 \pm 1{ }^{\circ} \mathrm{C}$ from $\sim 257$ BCE to $\sim 1686$ CE.

For comparison with the bubble number-density temperature estimates, we analyzed the ${ }^{18} \mathrm{O} /{ }^{16} \mathrm{O}$ ratios of ice in $50 \mathrm{~cm}$ long contiguous samples of the WDC06A core. The measurements were done at the University of Washington using equilibration at $35^{\circ} \mathrm{C}$ with $\mathrm{CO}_{2}$ (e.g. Craig, 1961) with a Micromass Isoprime mass spectrometer with 'Aquaprep' sample preparation system. Values are referenced to working standards calibrated to the International Atomic Energy Agency standards GISP (Greenland Ice Sheet Precipitation), SLAP (Standard Light Antarctic Precipitation) and VSMOW (Vienna Standard Mean Ocean Water), and reported using standard $\delta^{18} \mathrm{O}$ notation, expressed as a deviation (\%) from VSMOW. External accuracy of the measurements is $<0.1 \%$.

The $\delta^{18} \mathrm{O}$ data are shown in Figure 6, and are converted to approximate temperatures using the current average annual surface temperature for WAIS Divide of $\sim-31.1^{\circ} \mathrm{C}$,

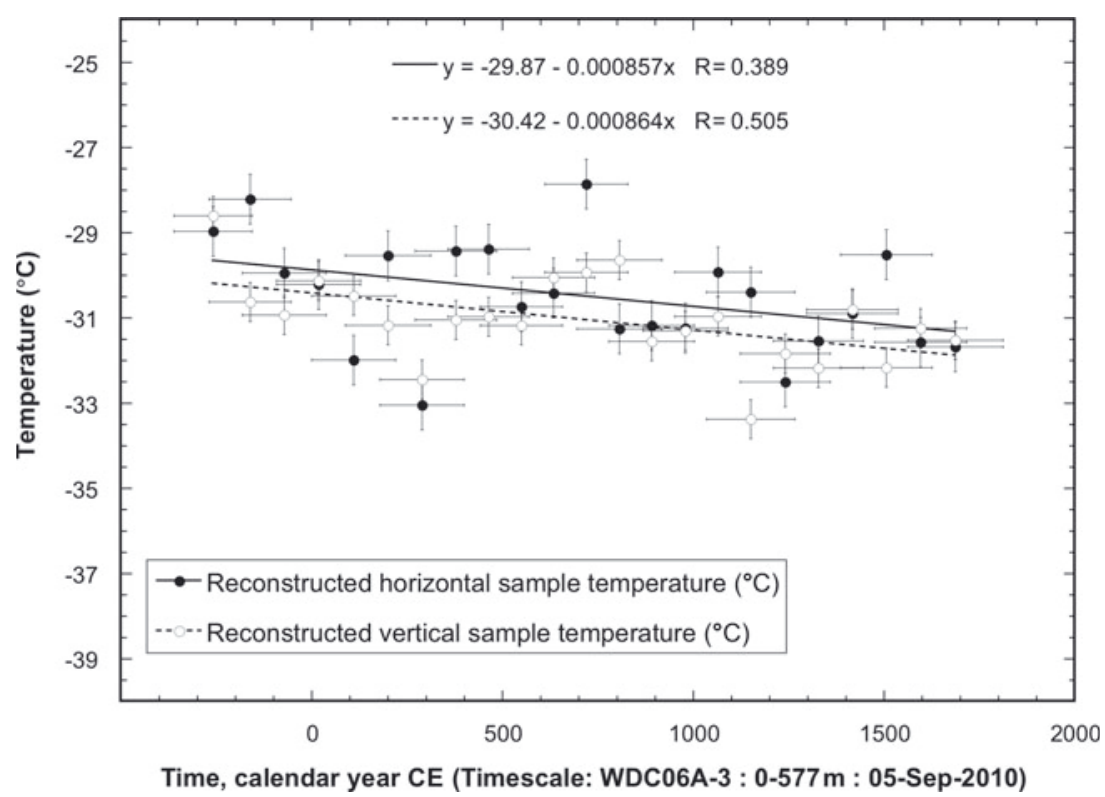

Fig. 5. Reconstructed temperatures plotted against age. Both horizontal and vertical samples show a similar decreasing linear trend. Error bars for temperature are derived from the bubble number-density standard deviation errors. 'Error bars' for age represent the averaging time for each sample. The linear regressions yield an average cooling of $\sim 1.66^{\circ} \mathrm{C}$. 


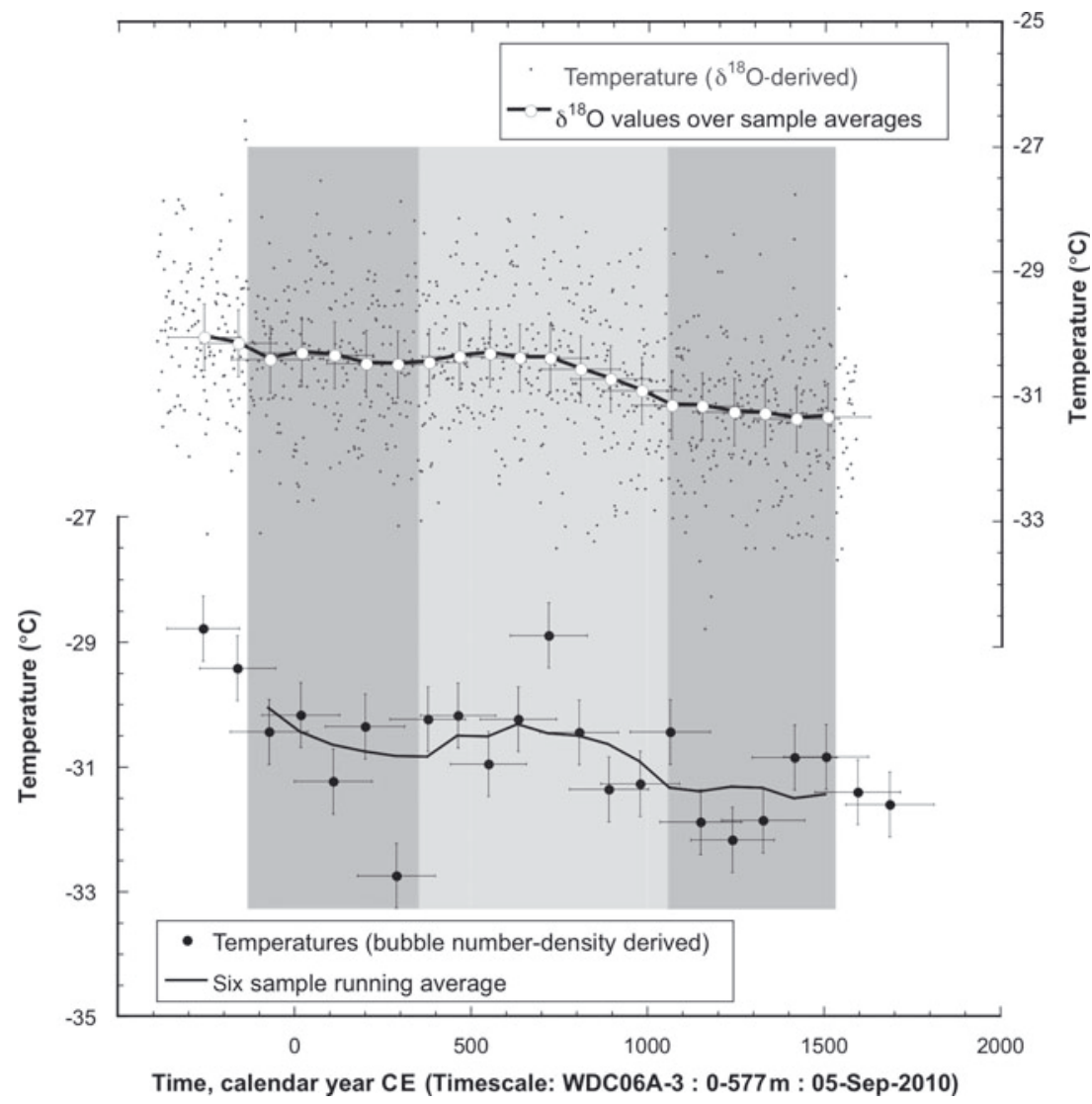

Fig. 6. Running-average temperature histories from $\delta^{18} \mathrm{O}$ (225 year average) and bubble number-density (six-sample). In each case, the temperature error bar is the $1 \sigma$ uncertainty of the average, and the horizontal bar is the averaging length. Shaded bands are added for ease of viewing, and to identify possibly interesting trends.

an approximation for the modern $\delta^{18} \mathrm{O}$ average value of $-33.6 \%$ and an assumed $\delta^{18} \mathrm{O}$ proxy calibration value of $\pm 0.8 \%$ representing $\pm 1{ }^{\circ} \mathrm{C}$ (Morgan, 1982). Agreement between the isotopic and bubble-number-density temperature trends is excellent.

\section{DISCUSSION}

Nearly constant measured bubble number-density is observed over time (Fig. 3). At constant temperature, the steady decrease in accumulation rate over time (Fig. 4) would have caused longer firnification times, hence formation of larger but fewer bubbles (Spencer, 1999). A decrease in temperature, slowing grain growth and thus reducing bubble size, increasing number-density and counteracting the effect of decreased accumulation, is thus indicated (Gow, 1969).

A decrease in accumulation rate often results from a decrease in temperature through dependence on the saturation vapor pressure, at $\sim 7 \%{ }^{\circ} \mathrm{C}^{-1}$ (Denton and others, 2005; Banta and others, 2008). The relation observed in the results from WAIS Divide is $9 \%{ }^{\circ} \mathrm{C}^{-1}$ (Fig. 7), consistent within the combined uncertainties.

The reconstructed temperature and accumulation rate applied where and when the ice was deposited. However, because both climate and the ice sheet can change, and ice is carried by flow even if the ice sheet is not changing, a reconstructed change in temperature or accumulation rate may have multiple causes. In our case, consideration of the modern flow field indicates that the reconstructed changes primarily reflect climate change. We first consider the nonlocal origin of the deeper ice analyzed, and then possible effects of changes in surface elevation over time.

The WAIS Divide site is $\sim 24 \mathrm{~km}$ on the Ross Sea side of the ice divide, so modern flow is bringing ice to the core site that was deposited as snowfall uphill and closer to the Amundsen Sea. Conway and Rasmussen (2009; see also Neumann and others, 2008) reported the modern flow velocity at the site as $\sim 3 \mathrm{~m} \mathrm{a}^{-1}$, decreasing up-glacier. Thus 2400 year old ice has come from $6-7 \mathrm{~km}$ up-glacier where the modern surface elevation is $\sim 5 \mathrm{~m}$ higher than at the drill site. Surface slopes in the vicinity of the core site show some variability (Conway and Rasmussen, 2009), and today the slope near the core site is not as steep as in regions both closer to the ice divide and down-flow of the core site. However, calculations using these steeper nearby slopes and the modern flow velocity yield a deposition site for 2400 year old ice only $\sim 10 \mathrm{~m}$ higher than at the core site. Assuming a lapse rate of $1^{\circ} \mathrm{C}(100 \mathrm{~m})^{-1}$ or slightly less, modern ice flow will have introduced an apparent warming of $<0.1^{\circ} \mathrm{C}$ over the length of our climate record, small compared to the observed signal. The modern accumulation rate decreases along ice flow in response to regional gradients, so the accumulation for the oldest ice in our sample was almost $5 \%$ larger than for the youngest ice (Conway and Rasmussen, 2009). Thus, about one-third of the apparent accumulation-rate change over time may have arisen from flow through the spatial accumulation-rate pattern, with the other two-thirds representing climate change.

At present, the site of the WAIS Divide core is nearly in balance, neither thickening nor thinning (Conway and 


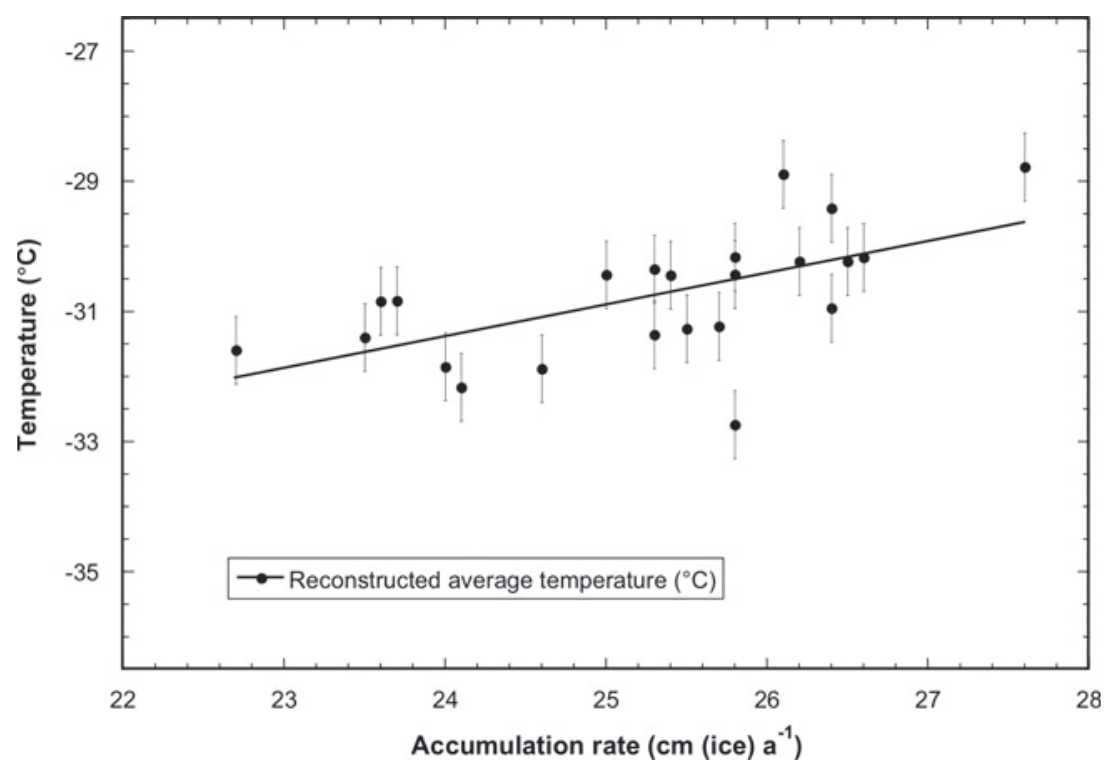

Fig. 7. Reconstructed average temperatures plotted against measured accumulation rates. Plot shows a $\sim 9 \%$ increase in accumulation rate per ${ }^{\circ} \mathrm{C}$ warming, broadly consistent with control by saturation vapor pressure. Error bars for temperature are derived from the bubble number-density standard deviation errors.

Rasmussen, 2009). However, $20 \mathrm{~km}$ down-flow toward the Ross Sea the ice is thickening by $0.1 \mathrm{~m} \mathrm{a}^{-1}$, and $30 \mathrm{~km}$ up-flow toward the Amundsen Sea the ice is thinning by $0.1 \mathrm{ma}^{-1}$. If a rate of $0.1 \mathrm{~m} \mathrm{a}^{-1}$ through a lapse rate of $1^{\circ} \mathrm{C}(100 \mathrm{~m})^{-1}$ had applied to the WAIS Divide site over the entire history of our climate record, then, depending on the sign, it could eliminate the entire climatic signal or double it. But, with the modern behavior at WAIS Divide, almost none of our signal was caused by changing surface elevation over time.

The ice divide is currently migrating toward the Ross Sea at $\sim 10 \mathrm{~m} \mathrm{a}^{-1}$, faster than the $3 \mathrm{~m} \mathrm{a}^{-1}$ flow of the ice (Conway and Rasmussen, 2009). If the entire thickness-change pattern has migrated with the divide, then the WAIS Divide site experienced elevation gain slightly less than $0.1 \mathrm{ma}^{-1}$ at the beginning of our record, dropping to zero recently. The resulting elevation change through the lapse rate might account for half of our reconstructed cooling. Given the large uncertainties, we have not attempted to use a detailed flow model to correct for ice flow, but we do not find a straightforward explanation of the entire signal based on ice flow.

An alternate approach is to examine the behavior of the site in a simulation of the deglaciation and Holocene in a whole-ice-sheet model. Recent three-dimensional West Antarctic ice sheet modeling results (Pollard and DeConto, 2009; personal communication from D. Pollard, 2009) indicate surface-elevation changes of $<100 \mathrm{~m}$ over the time interval corresponding to our study. Different model runs initialized in slightly different ways produce distinct trends, with both thickening and thinning observed, but consistently remaining small. Steig and others (2001) also found only small changes at the ice divide for a variety of model initial conditions. Strong conclusions should not be drawn from these modeling results, but they support our extrapolation from the data of Conway and Rasmussen (2009) that at least half and probably most of the reconstructed cooling represents a climatic change rather than an ice-flow effect.

Our reconstructed cooling has the appropriate sign for the expected effects of decreasing radiative equilibrium temperature in response to the effect of decreasing obliquity on summer duration (Huybers and Denton, 2008). There is no necessary conflict with the melt-layer results from relatively nearby Siple Dome showing midsummer warming over the same interval (Das and Alley, 2005, 2008), because those likely reflect midsummer conditions that are especially sensitive to midsummer insolation intensity, whereas the bubble number-density reflects mean annual temperature that is more sensitive to obliquity control on the seasonal distribution of intensity (Huybers and Denton, 2008).

Notably, however, $\delta^{18} \mathrm{O}$ data from both the nearby Byrd (Johnsen and others, 1972) and Siple Dome (Schiller, 2007) ice-coring sites appear to indicate a slight warming trend over the same period as in this study. Steig and others (2001) argued that Holocene trends at Byrd reflect ice-sheet thickness changes moving the surface through the atmospheric lapse rate, as well as the effects of horizontal ice flow causing older samples to have been deposited at higher, colder sites. Changes of order $100 \mathrm{~m}$ would be sufficient to significantly shift surface-temperature trends from climatic trends. Independent evidence points toward larger elevation changes at Byrd and Siple Dome than at WAIS Divide (Ackert and others, 1999, 2007), such that our interpretation of a primarily climatic cooling over the study interval at WAIS Divide does not necessarily indicate a different trend from those other sites.

\section{CONCLUSIONS}

The new paleoclimatic indicator based on ice-core bubble number-density developed by Spencer and others (2006), when applied to samples taken from the WAIS Divide WDC06A ice core, and with annual-layer thicknesses calculated from a chemistry-based depth-age scale, shows an approximately linear cooling of $\sim 1.7^{\circ} \mathrm{C}$ over the $\sim$ two millennia prior to $\sim 1700 \mathrm{CE}$. This cooling is consistent with $\delta^{18} \mathrm{O}$ isotope data for the WDC06A ice core. Additional work is required, but, either by extrapolating the modern ice-flow pattern back in time or by modeling the response of 
the sampling region to the deglaciation and Holocene, we find that a significant part of the reconstructed cooling represents climate change rather than the effects of ice flow. In turn, this cooling is consistent with Milankovitch obliquity forcing. The drop in temperature at WAIS Divide was accompanied by a decrease in accumulation rate, broadly consistent with dependence on saturation vapor pressure.

\section{ACKNOWLEDGEMENTS}

This work was supported by US National Science Foundation (NSF) grants 0539578 and 0539232. K. Walsh and $\mathrm{N}$. Reed assisted with bubble number-density measurements. The WAIS Divide Science Coordination Office at the Desert Research Institute of Reno, Nevada, was responsible for the collection and distribution of the WAIS Divide ice core and related tasks under NSF grants 0440817, 0230396 and 0944348. $\delta^{18} \mathrm{O}$ isotope data were obtained at the University of Washington under NSF grant 0537930. The depth-age scale and accumulation-rate data were determined at the Desert Research Institute under NSF grants 0839093, 0538427, 0739780 and 0944191. The NSF Office of Polar Programs also funds the Ice Drilling Program Office and Ice Drilling Design and Operations group for coring activities. The US National Ice Core Laboratory, which curated the core and performed core processing, is funded by the NSF. Raytheon Polar Services provided logistics support, and the 109th New York Air National Guard provided airlift support in Antarctica. We thank the hardworking people at all of these organizations. Lastly, we thank T. Sowers and D. Pollard for unpublished results, the US Geological Survey (USGS) Earth Surface Dynamics Program, and the $\Delta^{*}$ IsoLab at the University of Washington for assistance with the isotope measurements.

\section{REFERENCES}

Ackert, R.P., Jr and 6 others. 1999. Measurements of past ice sheet elevations in interior West Antarctica. Science, 286(5438), $276-280$

Ackert, R.P., S. Mukhopadhyay, B.R. Parizek and H.W. Borns. 2007. Ice elevation near the West Antarctic Ice Sheet divide during the Last Glaciation. Geophys. Res. Lett., 34(21), L21506. (10.1029/ 2007GL031412.)

Alley, R.B. 1987. Texture of polar firn for remote sensing. Ann. Glaciol., 9, 1-4.

Alley, R.B. and J.J. Fitzpatrick. 1999. Conditions for bubble elongation in cold ice-sheet ice. J. Glaciol., 45(149), 147-153.

Alley, R.B., A.J. Gow and D.A. Meese. 1995. Mapping $c$-axis fabrics to study physical processes in ice. J. Glaciol., 41(137), 197-203.

Banta, J.R., J.R. McConnell, M.M. Frey, R.C. Bales and K. Taylor. 2008. Spatial and temporal variability in snow accumulation at the West Antarctic Ice Sheet Divide over recent centuries. J. Geophys. Res., 113(D23), D23102. (10.1029/2008JD010235.)

Conway, H. and L.A. Rasmussen. 2009. Recent thinning and migration of the Western Divide, central West Antarctica. Geophys. Res. Lett., 36(12), L12502. (10.1029/2009GL038072.)

Conway, H. and 9 others. Unpublished. Candidate drill site near the Ross-Amundsen ice divide, West Antarctica. Report to the Ice Core Working Group, Madison, Wisconsin.

Craig, H. 1961. Isotopic variations in meteoric waters. Science, 133(3465), 1702-1703.

Cuffey, K.M. and W.S.B. Paterson. 2010. The physics of glaciers. Fourth edition. Oxford, Butterworth-Heinemann.

Cuffey, K.M., R.B. Alley, P.M. Grootes, J.M. Bolzan and S. Anandakrishnan. 1994. Calibration of the $\delta^{18} \mathrm{O}$ isotopic paleothermometer for central Greenland, using borehole temperatures. J. Glaciol., 40(135), 341-349.

Das, S.B. and R.B. Alley. 2005. Characterization and formation of melt layers in polar snow: observations and experiments from West Antarctica. J. Glaciol., 51(173), 307-313.

Das, S.B. and R.B. Alley. 2008. Rise in frequency of surface melting at Siple Dome through the Holocene: evidence for increasing marine influence on the climate of West Antarctica. J. Geophys. Res., 113(D2), D02112. (10.1029/2007JD008790.)

Denton, G.H., R.B. Alley, G.C. Comer and W.S. Broecker. 2005. The role of seasonality in abrupt climate change. Quat. Sci. Rev., 24(10-11), 1159-1182.

Epstein, S., R.P. Sharp and A.J. Gow. 1970. Antarctic ice sheet: stable isotope analyses of Byrd Station cores and interhemispheric climatic implications. Science, 168(3939), 1570-1572.

Gow, A.J. 1968a. Bubbles and bubble pressures in Antarctic glacier ice. J. Glaciol., 7(50), 167-182.

Gow, A.J. 1968b. Deep core studies of the accumulation and densification of snow at Byrd Station and Little America V, Antarctica. CRREL Res. Rep. 197.

Gow, A.J. 1969. On the rates of growth of grains and crystals in South Polar firn. J. Glaciol., 8(53), 241-252.

Gow, A.J. and 6 others. 1997. Physical and structural properties of the Greenland Ice Sheet Project 2 ice cores: a review. J. Geophys. Res., 102(C12), 26,559-26,575.

Herron, M.M. and C.C. Langway, Jr. 1980. Firn densification: an empirical model. J. Glaciol., 25(93), 373-385.

Huybers, P. and G.H. Denton. 2008. Antarctic temperature at orbital timescales controlled by local summer duration. Nature Geosci., 1(11), 787-792.

Ikeda-Fukazawa, T., T. Hondoh, T. Fukumura, H. Fukazawa and S. Mae. 2001. Variation in $\mathrm{N}_{2} / \mathrm{O}_{2}$ ratio of occluded air in Dome Fuji antarctic ice. J. Geophys. Res., 106(D16), 17,799-17,810.

Ikeda-Fukazawa, T. and 6 others. 2005. Effects of molecular diffusion on trapped gas composition in polar ice cores. Earth Planet. Sci. Lett., 229(3-4), 183-192.

Johnsen, S.J., W. Dansgaard, H.B. Clausen and C.C. Langway, Jr. 1972. Oxygen isotope profiles through the Antarctic and Greenland ice sheets. Nature, 235(5339), 429-434.

Lipenkov, V.Ya., P. Duval, T. Hondoh, A.N. Salamatin and N.I. Barkov. 1998. The climate signal in the air-bubble and airhydrate records obtained from the deep Vostok ice core. [Abstract A32B-21.] Eos, 79(45), Fall Meet. Suppl.

McGwire, K.C., J.R. McConnell, R.B. Alley, J.R. Banta, G.M. Hargreaves and K.C. Taylor. 2008. Dating annual layers of a shallow Antarctic ice core with an optical scanner. J. Glaciol., 54(188), 831-838.

Morgan, V.I. 1982. Antarctic ice sheet surface oxygen isotope values. J. Glaciol., 28(99), 315-323.

Neumann, T.A., H. Conway, E. Waddington, G.A. Catania and D.L. Morse. 2008. Holocene accumulation and ice sheet dynamics in central West Antarctica. J. Geophys. Res., 113(F2), F02018. (10.1029/2007JF000764.)

Nye, J.F. 1963. Correction factor for accumulation measured by the thickness of the annual layers in an ice sheet. J. Glaciol., 4(36), 785-788.

Pauer, F., J. Kipfstuhl, W.F. Kuhs and H. Shoji. 1999. Air clathrate crystals from the GRIP deep ice core: a number-, size- and shape-distribution study. J. Glaciol., 45(149), 22-30.

Pollard, D. and R.M. DeConto. 2009. Modelling West Antarctic ice sheet growth and collapse through the past five million years. Nature, 458(7236), 329-332.

Salamatin, A.N., T. Hondoh, T. Uchida and V.Y. Lipenkov. 1998. Post-nucleation conversion of an air bubble to clathrate airhydrate crystal in ice. J. Cryst. Growth, 193(1-2), 197-218.

Schiller, A.S.M. 2007. The stable isotopes and deuterium excess from the Siple Dome ice core: implications for the late Quaternary climate and elevation history of the Ross Sea Region, West Antarctica. (PhD thesis, University of Colorado at Boulder.) 
Schneider, D.P. and E.J. Steig. 2008. Ice cores record significant 1940s Antarctic warmth related to tropical climate variability. Proc. Natl Acad. Sci. USA (PNAS), 105(34), 12,154-12,158.

Severinghaus, J.P., T. Sowers, E.J. Brook, R.B. Alley and M.L. Bender. 1998. Timing of abrupt climate change at the end of the Younger Dryas interval from thermally fractionated gases in polar ice. Nature, 391(6663), 141-146.

Shoji, H. and C.C. Langway, Jr. 1982. Air hydrate inclusions in fresh ice core. Nature, 298(5874), 548-550.

Solomon, S. and 7 others, eds. 2007. Climate change 2007: the physical science basis. Contribution of Working Group I to the Fourth Assessment Report of the Intergovernmental Panel on Climate Change. Cambridge, etc., Cambridge University Press.

Sowers, T., M. Bender, D. Raynaud and Y. Korotkevich. 1992. $\delta^{15} \mathrm{~N}$ of $\mathrm{N}_{2}$ in air trapped in polar ice: a tracer of gas transport in the firn and a possible constraint on ice age-gas age differences. J. Geophys. Res., 97(D14), 15,683-15,697.
Spencer, M.K. 1999. Polar firn densification: developing a forward model. (MSc thesis, Pennsylvania State University.)

Spencer, M.K., R.B. Alley and J.J. Fitzpatrick. 2006. Developing a bubble number-density paleoclimatic indicator for glacier ice. J. Glaciol., 52(178), 358-364.

Steig, E.J. and 6 others. 2001. West Antarctic ice sheet elevation changes. In The West Antarctic ice sheet: behavior and environment. Washington, DC, American Geophysical Union, 75-90. (Antarctic Research Series 77.)

Steig, E.J., D.P. Schneider, S.D. Rutherford, M.E. Mann, J.C. Comiso and D.T. Shindell. 2009. Warming of the Antarctic ice-sheet surface since the 1957 International Geophysical Year. Nature, 457(7228), 459-462.

Taylor, K.C. and 13 others. 2004. Dating the Siple Dome (Antarctica) ice core by manual and computer interpretation of annual layering. J. Glaciol., 50(170), 453-461.

Underwood, E.E. 1970. Quantitative stereology. Reading, MA Addison-Wesley.

MS received 3 November 2010 and accepted in revised form 4 April 2011 